\title{
Health care utilization and outpatient, out-of-pocket costs for active convulsive epilepsy in rural northeastern South Africa: a cross-sectional Survey
}

Ryan G. Wagner ${ }^{1,2,3^{*}}$, Melanie Y. Bertram ${ }^{4}$, F. Xavier Gómez-Olivé2, ${ }^{2}$, Stephen M. Tollman ${ }^{1,2,3,5}$, Lars Lindholm³, Charles R. Newton ${ }^{1,2,6,7,8,9}$ and Karen J. Hofman ${ }^{2,10}$

\begin{abstract}
Background: Epilepsy is a common neurological disorder, with over $80 \%$ of cases found in low- and middle-income countries (LMICS). Studies from high-income countries find a significant economic burden associated with epilepsy, yet few studies from LMICs, where out-of-pocket costs for general healthcare can be substantial, have assessed out-of-pocket costs and health care utilization for outpatient epilepsy care.

Methods: Within an established health and socio-demographic surveillance system in rural South Africa, a questionnaire to assess self-reported health care utilization and time spent traveling to and waiting to be seen at health facilities was administered to 250 individuals, previously diagnosed with active convulsive epilepsy. Epilepsy patients' out-of-pocket, medical and non-medical costs and frequency of outpatient care visits during the previous 12-months were determined.

Results: Within the last year, 132 (53\%) individuals reported consulting at a clinic, 162 (65\%) at a hospital and 34 (14\%) with traditional healers for epilepsy care. Sixty-seven percent of individuals reported previously consulting with both biomedical caregivers and traditional healers. Direct outpatient, median costs per visit varied significantly $(p<0.001)$ between hospital (2010 International dollar (\$) 9.08; IQR: \$6.41-\$12.83) and clinic consultations (\$1.74; IQR: \$0-\$5.58). Traditional healer fees per visit were found to cost \$52.36 (IQR: \$34.90-\$87.26) per visit. Average annual outpatient, clinic and hospital out-of-pocket costs totaled $\$ 58.41$. Traveling to and from and waiting to be seen by the caregiver at the hospital took significantly longer than at the clinic.

Conclusions: Rural South Africans with epilepsy consult with both biomedical caregivers and traditional healers for both epilepsy and non-epilepsy care. Traditional healers were the most expensive mode of care, though utilized less often. While higher out-of-pocket costs were incurred at hospital visits, more people with ACE visited hospitals than clinics for epilepsy care. Promoting increased use and effective care at clinics and reducing travel and waiting times could substantially reduce the out-of-pocket costs of outpatient epilepsy care.
\end{abstract}

Keywords: Africa, Direct medical costs, Indirect medical costs, Population-based, Chronic disease

\footnotetext{
* Correspondence: Ryan.wagner@wits.ac.za

${ }^{1}$ Studies of Epidemiology of Epilepsy in Demographic Surveillance Systems (SEEDS) - INDEPTH Network, Accra, Ghana

${ }^{2}$ MRCMits Rural Public Health \& Health Transitions Research Unit (Agincourt),

School of Public Health, Faculty of Health Sciences, University of the

Witwatersrand, Johannesburg, South Africa

Full list of author information is available at the end of the article
} 


\section{Background}

Epilepsy is a common neurological disorder with $80 \%$ of all cases found in low- and middle-income countries (LMICs) [1]. Ten million people live with epilepsy on the African continent alone [2]. Studies from LMICs have quantified the epidemiological burden of epilepsy consistently showing higher incidence [3] and mortality [4] associated with epilepsy. However, few populationbased studies have explored the utilization and cost of health care due to epilepsy in these countries, with no known studies from South Africa.

Due to its chronic, stigmatizing, and often debilitating nature, epilepsy carries significant economic costs in terms of both medical treatment and lost economic productivity [5]. Studies have found costs to vary by seizure type and frequency, temporal stage of the disorder, diagnostic and treatment tools available, and the frequency and type of health care services utilized by people with epilepsy [6]. A review of 22 cost-of-illness studies on epilepsy from both low- and middle-income and high-income countries found mean annual direct costs (costs related to seeking and receiving care for epilepsy) to range from 2006 International dollar (\$) 40 to $\$ 4768$, with costs substantially lower in LMICs, ranging from $\$ 40$ to $\$ 384$ [7]. Anti-epileptic drugs (AEDs) and hospital admissions are major drivers of direct costs associated with epilepsy treatment [7].

The few African studies that exist find that costs due to epilepsy can be substantial, with the majority of costs due to AEDs [7]. A population-based Burundian study found people with epilepsy to have significantly higher annual health care costs than those without any neurological condition, with those taking AEDs experiencing a $440 \%$ increase [8]. A Nigerian study, exploring the cost of pediatric epilepsy at a tertiary health facility, found that more than half of all families with a household member with epilepsy spent more than $20 \%$ of the family's total income on their care [9].

\section{Health care utilization}

Health care utilization is an important component of both costs and adherence, with the relationship between these factors often bidirectional and complex [10, 11]. Studies from high-income countries show that people with epilepsy utilize health care more often than people without epilepsy due to repeat drug prescriptions [12] and increased emergency room usage [13].

Existing studies in LMICs find a large epilepsy treatment gap - defined as those not on treatment or on inadequate treatment [14]. An analysis of 27 studies from LMICs found an overall treatment gap of $56 \%$ [15]. This suggests that people do not utilize (or receive) the health care they need. Cost of treatment, unavailability of drugs, and inadequate healthcare manpower all contributed significantly to the observed treatment gap [15]. By understanding costs and health care utilization for people with epilepsy, interventions to remove barriers and improve access to care can be developed. In South Africa, where standard AEDs are provided free of charge, understanding drivers of out-of-pocket costs and time spent seeking health care may provide insights on how to reduce the treatment gap.

In the current study, we determined the health care utilization of people with active convulsive epilepsy, estimated the time spent seeking outpatient treatment and calculated direct out-of-pocket costs in a rural South African context. This is the first study of its kind from South Africa.

\section{Methods}

\section{Study area and population}

The Agincourt Health and Socio-Demographic Surveillance System (HDSS) site, located in the Agincourt health sub-district of the Bushbuckridge municipality, comprises $420 \mathrm{~km}^{2}$ of semi-arid, rural scrubland, $500 \mathrm{~km}$ northeast of Johannesburg, South Africa in Mpumalanga Province adjacent to Mozambique. Established as a research site in 1992, the Agincourt HDSS (http://www.agincourt.co.za) aims to inform health and development policy through evidence-based research and has generated sociodemographic data since its inception through annual census updates that capture vital statistics, including births, deaths, and in- and out-migrations.

The 2011 mid-year population was roughly 90,000 individuals in 16,000 households and 27 research villages [16]. The majority of the population speaks Xitsonga with one-third of the population of Mozambican origin.

Unemployment remains high in Agincourt with $36 \%$ of the adult population (older than 18 years old) unemployed and currently looking for work [17]. The socio-economic status of the site has improved over the last 20 years, though as of 2011, $20 \%$ of the population was still living in extreme poverty (personal communication, Mark Collinson). Government grants provide much needed financial support, with the majority of Agincourt households receiving at least one (personal communication, Mark Collinson).

Within the Agincourt site, a network of six, government primary health care (PHC) clinics offers free basic, outpatient health services during regular business hours. These services include mother and child care, including immunizations, family planning, testing and treatment for sexually transmitted infections, including HIV, minor trauma and routine care for those with chronic conditions, including epilepsy [18].

The six clinics refer patients to one larger government community health centre within the site. The health centre provides PHC services as well as 24-h acute care and facilities for 48-h patient observation [18]. Nurses 
run both clinics and health centres, though doctors do visit clinics and health centres.

A public-private partnership community health centre within the site provides HIV, tuberculosis and other chronic disease care and treatment. Clinicians staff this facility.

Referrals from primary health care facilities in the Agincourt research site are made to three government hospitals located $25-55 \mathrm{~km}$ from the site. Clinicians at the hospitals primarily diagnose epilepsy and initiate therapy before referring patients to the clinics or health centre for monthly AED collection [19]. People with epilepsy are expected to return to the hospital at 6-month intervals for review of seizure frequency and treatment.

\section{Case definition and case ascertainment}

A 2008 cross-sectional survey sought to identify all individuals with active convulsive epilepsy (ACE) living within the Agincourt HDSS [20]. ACE was defined as having $\geq 2$ unprovoked convulsive seizures occurring more than $24 \mathrm{~h}$ apart, with at least one seizure occurring in the year preceding the study or currently taking AEDs for epilepsy [20]. After undergoing a clinical history and neurological exam, 311 individuals living within the Agincourt HDSS were diagnosed with ACE by the study neurologist (CRN), yielding an adjusted ACE prevalence of 7.0 per 1000 individuals [20].

\section{Data collection}

Between September 2010 and January 2011, trained fieldworkers attempted to visit each individual diagnosed with $\mathrm{ACE}$ and/or his/her caregiver. If consent was given, the respondent was asked questions regarding health care utilization over the previous 12-months. Questions on outof-pocket costs associated with utilization of outpatient care for the treatment of ACE were asked regarding the last visit to the biomedical health care facility. The questionnaire was forward- and back- translated into the local language and piloted with local community members. The English version of the questionnaire is available as an Additional file (Additional file 1).

\section{Statistical analysis}

The questionnaires were entered into a mySQL database (OracleCorp, Redwood Shores, CA, U.S.A) by a trained data typist and the data analyzed using Stata 13 (StataCorp, College Station, TX, U.S.A). Due to the non-normal distribution of health care and traditional healer visits and out-of-pocket costs $(p<0.0001$ when performing the Shapiro-Wilk test of normalcy), we report results as median and interquartile range.

The annual cost of outpatient, out-of-pocket care was calculated by multiplying the average cost per visit by the average number of visits reported in the last 12months.

The time traveling to a traditional healer was not collected in this study and only traditional healer fees are reported as results.

\section{Results}

Household visits were made to all 311 individuals diagnosed with ACE in 2008; 20 were found to be deceased, 8 had permanently out-migrated from the study area, 9 refused to participate in the study and 24 were not available after visiting the household on at least 3 separate occasions. There was no significant age or sex variation between respondents and non-respondents. Of those alive and found, 250 individuals (97\%) agreed to take part in the study with a male-to-female ratio of 1.05 . The median age was 29 (inter-quartile range: $25^{\text {th }}$ percentile- $75^{\text {th }}$ percentile (IQR): $18-44$ years). Seven (14\%) of those older than 18 years were currently employed whilst $33(50 \%)$ of those younger than 18 years were currently in school. One hundred forty-eight individuals (59\%) were receiving an epilepsy-related, government disability grant of $\$ 188$ per month, whilst 4 individuals $(2 \%)$ reported receiving smaller non-epilepsy-related grant amounts ranging from \$44-176 (Table 1).

\section{General health care utilization in people with epilepsy}

Two hundred thirty-nine $(96 \%)$ individuals reported receiving non-epilepsy related health care when they last needed it, which for 154 individuals $(62 \%)$ was in the previous 30-days. For 231 (91 \%) individuals, it was in the last year. Four individuals $(1 \%)$ reported being denied care and one participant cited inadequate levels of biomedical caregiver's skill as reason for not receiving the necessary health care. Six individuals did not report the reason for not receiving care when they last needed it.

One hundred eighty-four (74\%) had ever sought general care from both a biomedical facility (hospital, health centre, or clinic) and a traditional healer, whilst 63 individuals $(25 \%)$ only sought general care from a biomedical facility and 1 person sought general care only from a traditional healer.

\section{Epilepsy-related health care utilization}

Within the last year, 132 people with epilepsy (53\%) report consulting for epilepsy at a clinic, $162(65 \%)$ at a hospital and $34(14 \%)$ with traditional healers. One hundred sixty-eight individuals $(67 \%)$ reported previously seeking epilepsy care from both a biomedical facility and a traditional healer, whilst 61 individuals (24 \%) have sought care from only biomedical facilities. Eleven individuals (4\%) reported only seeking care for epilepsy from traditional healers, whilst 10 individuals sought no care- neither from a biomedical facility nor a traditional healer. People 
Table 1 Socio-demographic characteristics of study participants (n)

\begin{tabular}{|c|c|}
\hline & n (\%) \\
\hline \multicolumn{2}{|l|}{ Age band } \\
\hline $0-5$ & $9(4)$ \\
\hline $6-12$ & $27(11)$ \\
\hline $13-18$ & $31(12)$ \\
\hline $19-28$ & $54(22)$ \\
\hline $29-49$ & $85(34)$ \\
\hline $50+$ & $44(17)$ \\
\hline \multicolumn{2}{|l|}{ Sex } \\
\hline Male & $128(51)$ \\
\hline Female & $122(49)$ \\
\hline \multicolumn{2}{|c|}{ Receiving government grant } \\
\hline Yes & $153(61)$ \\
\hline No & $97(29)$ \\
\hline \multicolumn{2}{|c|}{ Socio-Economic Status ${ }^{\mathrm{a}}$} \\
\hline 1st Quintile & $31(13)$ \\
\hline 2nd Quintile & $65(27)$ \\
\hline 3rd Quintile & $50(20)$ \\
\hline 4th Quintile & $50(20)$ \\
\hline 5th Quintile & $49(20)$ \\
\hline \multicolumn{2}{|c|}{ Currently employed (if $>18$ years old) } \\
\hline Yes & $14(8)$ \\
\hline No & $169(92)$ \\
\hline \multicolumn{2}{|c|}{ Currently in school (if $<18$ years old) } \\
\hline Yes & $33(49)$ \\
\hline No & $34(51)$ \\
\hline
\end{tabular}

aderived from 2009 Agincourt SES module; 5 missing data

with epilepsy sought general care at the government clinic more frequently than epilepsy-related care (94\% versus $76 \%$ ), whilst utilizing hospital care at similar levels for both epilepsy and general care (91 \% versus $86 \%$ ) (Table 2). The average number of hospital visits in the previous 12-months was 4.06 (standard deviation (SD): 4.75) and average number of clinic visits was 6.5 (SD: $5.75)$.

\section{Costs of biomedical health care utilization}

The median cost per clinic visit was found to be $\$ 1.74$ (IQR: \$0-\$4.80) (mean: 2.74; SD 3.74), whilst the median cost per outpatient hospital visit was found to be $\$ 9.08$
(IQR: \$6.11-\$12.91) (mean: 9.73; SD 5.34) - a statistically significant difference $(p<0.001)$. The costs for epilepsy care at clinic and hopsital can be found in Table 3. The average annual cost for out-of-pocket, outpatient biomedical care at a clinic or hospital was found to be $\$ 58.41$.

The median travel and waiting time at the hospital was twice that of the clinic $(120 \mathrm{~min} / 60 \mathrm{~min}$ and $240 \mathrm{~min} / 120 \mathrm{~min}$, respectively), whilst the time spent with a health professional was the same (10 min) (Table 4). The majority of respondents walked to the clinic but took a public taxi to the hospital. During their last visit to the hospital, $30 \%$ of respondents saw a physician and $70 \%$ saw a nurse. During their last visit to the clinic, $11 \%$ saw a physician and $89 \%$ saw a nurse.

\section{Costs of traditional healer utilization}

During the last visit to a traditional healer 160 individuals $(87 \%)$ had to pay for services, with payment in all cases being cash. The median cost for a traditional healer's services was $\$ 52.36$ (\$34.90-\$87.26). One individual reported only having to pay the traditional healer if $\mathrm{s} / \mathrm{he}$ was cured of epilepsy.

\section{Discussion}

We found that the majority of people with ACE (91\%) needed non-epilepsy care in the previous year, which was similar to the $87 \%$ percent in those greater than 50 years old who reported needing care within the previous year in a separate study within the same site [21]. Additionally, $53 \%$ of people with ACE sought care for epilepsy from a clinic and $65 \%$ from a hospital in the previous year. One limitation of the current study is that we have no indication as to whether the utilization of outpatient, biomedical care was routine or the result of an epilepsy-related emergency. Future investigation is warranted to address this.

Findings from high-income countries suggest that people with epilepsy utilize health care more often than individuals with other chronic conditions, including asthma, diabetes and migraines $[12,13,22]$. People with epilepsy in the Agincourt sub-district are required to visit the clinic once per month to collect AEDs. This requirement may result in the higher clinic utilization levels found in people with epilepsy when compared to those greater than 50 years old with other chronic conditions in the area [23]. Further work to ascertain the reasons for increased health care utilization and to determine whether people with epilepsy benefit from

Table 2 Lifetime utilization of care by people with epilepsy \& median number of visits in previous year, Agincourt 2010-11 ( $n=250)$

\begin{tabular}{lllll}
\hline & $\begin{array}{l}\text { Ever sought attention } \\
\text { for General care (\%) }\end{array}$ & $\begin{array}{l}\text { Median visits in previous } \\
12 \text {-months (IQR) }\end{array}$ & $\begin{array}{l}\text { Ever sought attention for } \\
\text { epilepsy-related care (\%) }\end{array}$ & $\begin{array}{l}\text { Median visits in previous } \\
12 \text {-months (IQR) }\end{array}$ \\
\hline Government Clinic & $235(94)$ & $1(0-5)$ & $189(76)$ & $10(0-11)$ \\
Government Hospital & $228(91)$ & $0(0-1)$ & $216(86)$ & $2(0-10)$ \\
Traditional Healer & $185(74)$ & $0(0-0)$ & $179(73)$ & $0(0-0)$ \\
\hline
\end{tabular}


Table 3 Median direct costs for epilepsy care at clinic and hospital, Agincourt 2010-11

\begin{tabular}{lll}
\hline & Clinic & Hospital \\
\hline $\begin{array}{l}\text { Direct Medical Costs (per visit) } \\
\text { Epilepsy Medication }\end{array}$ & $0(0-0)$ & $0(0-0)$ \\
$\begin{array}{l}\text { Opening file } \\
\begin{array}{l}\text { Direct Non-Medical Costs } \\
\text { (per visit) }\end{array}\end{array}$ & $\$ 3.49(3.49-5.24)$ & $\$ 3.49(3.49-3.49)$ \\
$\begin{array}{l}\text { Transportation } \\
\begin{array}{l}\text { Food/drink purchased } \\
\text { due to visit }\end{array}\end{array}$ & $\$ 2.79(1.74-4.89)$ & $\$ 5.41(4.19-7.68)$ \\
\hline
\end{tabular}

Median (IQR)

Expressed in 2010 International dollars \$

the care they seek in this rural southern African setting is also warranted.

People with epilepsy were more likely to utilize public clinics for non-epilepsy care, whilst more likely to utilize public hospitals for epilepsy care. The frequency of the visits to the clinic, for both general care and epilepsyrelated care, was greater than the frequency of hospital visits. The reason for more people seeking care at the hospital rather than the clinic is unclear. Perceived inadequacy of skilled manpower has been cited as a cause for people not seeking care in a number of studies from LMICs [24-26], and the perception of 'more adequate' manpower at the hospital (even though only $30 \%$ of patients saw a doctor at the hospital, compared to $11 \%$ at the clinic) could potentially explain a patient's preference to attend hospital for epilepsy care.

The non-availability of AEDs has also been shown to affect care-seeking patterns [15] and is another possible reason that some people with epilepsy chose to seek care at the hospital rather than the clinic. Hospitals, with larger catchment areas, are likely to have a more continuous

Table 4 Time associated with seeking epilepsy care (traveling, waiting and consulting), Agincourt 2010-11

\begin{tabular}{clll}
\hline Travel Time & $\begin{array}{l}\text { Median Time } \\
\text { (in minutes) }\end{array}$ & IQR & Mode of Transport \\
\hline to Clinic & 60 & $40-90$ & $62 \%$ walked, 38 \% public taxi \\
to Hospital & 120 & $120-240$ & $\begin{array}{l}92 \% \text { public taxi, 4 \% walked, } \\
3 \% \text { hired car, } 1 \% \text { personal car }\end{array}$ \\
Waiting Time & & & \\
to Clinic & 120 & $10-420$ & \\
to Hospital & 240 & $30-600$ & \\
Time with Health Professional & & Health Professional Seen \\
to Clinic & 10 & $9-15$ & $11 \%$ physician, 89 \% nurse \\
to Hospital & 10 & $10-15$ & $30 \%$ physician, 70\% nurse \\
Time Totals & & & \\
Clinic & $220^{*}$ & $140-310$ & \\
Hospital & $490^{*}$ & $320-610$ & \\
${ }^{*} p<0.0001$ & &
\end{tabular}

supply of medication. In this study, $10 \%$ of patients reported that drugs are not always available and $22 \%$ of patients reported that the lack of drugs discouraged them from utilizing the health facility. While this study didn't explore the percentage of stock-outs at each facility, this research does suggest that improving drug supply could encourage better PHC facility attendance.

\section{Traditional healer utilization}

We found disclosed lifetime traditional healer usage to be high in people with epilepsy for both epilepsy- and non-epilepsy-related care (73\% and $74 \%$, respectively), although the frequency of visits for both general and epilepsy-related care was substantially less than visits to both biomedical facilities within the 12 months preceding this study. A national South African survey found similar patterns, though lower utilization levels, and suggests that poorer, rural, black populations utilize traditional healers more than urban, non-black populations [27].

Utilization of traditional healers within the previous 12 months was low when compared to those who reported ever seeking traditional healer care for epilepsy. It may be that traditional healer care was sought during the initial onset of seizures and care discontinued as the seizures continued and traditional treatment proved ineffective. Still, nearly $15 \%$ of people with epilepsy reported at least one visit to the traditional healer for epilepsy care within the previous 12-months.

Our research concurs with findings that suggest the costs associated with traditional healers are substantially higher than costs of seeking care at biomedical facilities [28]. The traditional healers' costs we present only include traditional healers' fees and do not include time and money spent traveling to and waiting to be seen by a traditional healer, which would likely increase the total costs. Our results likely represent the lower bound of costs associated with traditional healer costs. The higher cost per visit may be financially prohibitive and result in the lower frequency of utilization. Furthermore, the aggregate cost of traditional healers, taking into account the lower frequency but higher per visit cost, may be similar to the cost of biomedical facilities, which are utilized more often, but cost, per visit, substantially less.

Understanding determinants of traditional healer utilization in this context is warranted as the cultural understanding of epilepsy has been shown to be an important determinant in care-seeking behavior [29]. Identifying ways of working with traditional healers to reduce the epilepsy treatment gap, however, may be more productive than attempting to change individual's behavior.

\section{Costs associated with epilepsy treatment}

Seeking care at the hospital took significantly longer and cost significantly more- more than twice the cost of 
seeking care at the clinic. As costs (including lost time) associated with seeking epilepsy treatment have commonly been found to be associated with the epilepsy treatment gap [15], increasing the utilization of care at clinics by strengthening epilepsy care delivery will likely reduce costs and potentially improve the treatment gap. Furthermore, reducing transportation cost could result in an overall reduction in out-of-pocket costs given that transportation costs have been highlighted as a significant cost in previous work in the area [28].

The overall annual out-of-pocket costs for out-patient epilepsy care at biomedical facilities was found to be $\$ 58.41$, on average, yet this only represents a portion of the total cost of epilepsy care in rural South Africa.

\section{AED costs}

Patients' AED costs are likely to be lower in South Africa than other LMICs due to the free availability of AEDs at health facilities. No patient reported paying for AEDs in this study. In contrast, two other African studies found AEDs to contribute $10 \%$ [8] and $22 \%$ [9] of the total direct epilepsy treatment-related costs. One study from rural Kenya found that people with epilepsy who had to pay for AEDs were less likely to seek care [30], suggesting that reducing or removing the cost of AEDs might improve accessibility and consequently adherence [31]. Future work exploring adherence patterns in South Africa, where AEDS are free, is warranted and could be a natural experiment to establish whether free availability of AEDs to patients truly does improve adherence.

\section{Limitations}

While this study presents previously unavailable information on utilization patterns and out-of-pocket costs for people with ACE in rural South Africa, there are a number of potential limitations.

We only examined people with ACE in this study. We recognize that this cohort does not represent all epilepsies and limits the interpretation of the results of this study to people with ACE only. However, convulsive epilepsies are often associated with the largest morbidity, stigma and mortality [32] and potentially pose a greater burden to individuals and families compared to non-convulsive epilepsies.

This study did not measure indirect costs associated with ACE, whilst a number of studies have found that this cost can be significant- ranging from $12 \%$ to $85 \%$ of the total annual costs due to epilepsy [7]. As such, this study likely underestimates the total cost of ACE. This study also only explored out-of-pocket, outpatient costs associated with ACE and did not include costs associated with hospital admissions or epilepsy-related surgeries (in-patient costs). Studies from Italy have found in-patient costs to be significant, especially in new-onset epilepsy [33, 34]. This study only examined ACE, and outpatient treatment patterns and costs for other types of epilepsy may vary; however, further studies are needed to verify this.

We chose an out-of-pocket costing approach for this study. In countries, such as South Africa, with high levels of unemployment and substantial inequality, using the GDP per capita as a proxy for productivity may not represent the actual productivity loss due to epilepsy and, some argue, fails to account for the value of human life $[35,36]$. As such, a wider, societal costing approach was not adopted in this study. Further development of methodologies to allow for the accurate calculation of productivity costs in areas of high unemployment where formal sector employment is scarce is needed.

All costs and utilization analyzed in this study were self-reported. Recall bias or intentional bias in reporting may result in misreporting of costs and utilization associated with seeking epilepsy care. Every effort, through careful probing by well-trained fieldworkers, was made to ensure the collection of accurate data.

Finally, this study only explored out-of-pocket costs of epilepsy to the patient. Given the free availability of AEDs in South Africa and the subsidized direct, medical health care costs within the public healthcare system, epilepsy-related treatment costs to the health care system are potentially greater than in other African countries.

\section{Conclusions}

Out-of-pocket, direct, outpatient costs are likely to contribute only a portion of the total economic burden of epilepsy, with further research needed to determine inpatient care costs as well as indirect costs attributable to epilepsy in rural South Africa. However, this research suggests that rural South African patients spend more time and money seeking epilepsy care from a hospital than from a clinic and readily seek both biomedical and traditional healthcare. Interventions aimed at strengthening epilepsy care at the primary care clinic, including regular drug supply chains, and reducing the amount of time spent traveling to and waiting to be seen at biomedical facilities could substantially reduce the out-of-pocket costs experienced by people with active convulsive epilepsy.

\section{Additional file}

\section{Additional file 1: Questionnaire used for data collection, Agincourt} 2010. (DOCX $153 \mathrm{~kb}$ )

\section{Abbreviations}

\$, International dollar; ACE, Active convulsive epilepsy; AEDs, Anti-epileptic drugs; HDSS, Health and demographic surveillance system; IQR, interquartile range; LMICS, Low- and middle- income countries; PHC, primary health care 


\section{Acknowledgements}

The authors wish to acknowledge Ms. Rachael Odhiambo for developing and overseeing the study's database as well as the fieldworkers of the MRCNits Agincourt Research Unit involved in the Studies of the Epidemiology of Epilepsy in Demographic Surveillance Systems (SEEDS) study and the Agincourt sub-district population who took part in the study.

\section{Funding}

This study was funded through the Priority Cost-effective Lessons for Systems Strengthening (PRICELESS) directorate, a sub-award through the University of Washington from the Bill \& Melinda Gates Foundation. The Agincourt HDSS is funded by the Wellcome Trust, UK (grants 069683/Z/02/Z; 085477/Z/08/Z), with important contributions from the University of the Witwatersrand, the South African Medical Research Council, and National Institute on Aging (NIA) of the National Institutes of Health (NIH). RGW is supported by the European Union International Research Staff Exchange Scheme (grant no. 295168) and CRN is funded by the Wellcome Trust, UK (083744).

\section{Availability of data and materials}

The data supporting the findings of this manuscript can be obtained on request from the Agincourt HDSS data manager

(DataManager@agincourt.co.za) as part of the Studies of the Epidemiology of Epilepsy in Demographic Surveillance Systems (Epidemiology and Treatment of Epilepsy in sub-Saharan Africa) database. The questionnaire used in this study can be found as an Additional file (Additional file 1) to this manuscript.

\section{Authors' contributions}

All authors participated in the conception the study and designed the data collection tool. RGW, FXGO and ST oversaw the data collection. RGW conducted the data analysis and interpretation with support from MYB, CRN and LL. RGW wrote the first draft of the manuscript with significant support from MYB, CRN, KH and LL. All authors read and approved the final version of this manuscript.

\section{Competing interests}

The authors declare that they have no competing interests. MYB is a staff member of the WHO. The author alone is responsible for the views expressed in this publication and they do not necessarily represent the decisions, policy, or views of the $\mathrm{WHO}$

\section{Consent for publication \\ Not applicable.}

\section{Ethics approval and consent to participate}

Ethical clearance for the study was received from the Human Research Ethics Committee at the University of the Witwatersrand, Johannesburg, (Clearance number: M10566) and the Mpumalanga Provincial Research and Ethics Committee. Written, informed consent was sought from each participant in the study. Parental or guardian informed consent was sought when the person with epilepsy was a child or individual with impaired cognition. Verbal assent was also received from the child or individual with impaired cognition.

\section{Author details}

${ }^{1}$ Studies of Epidemiology of Epilepsy in Demographic Surveillance Systems (SEEDS) - INDEPTH Network, Accra, Ghana. ${ }^{2}$ MRC/Wits Rural Public Health \& Health Transitions Research Unit (Agincourt), School of Public Health, Faculty of Health Sciences, University of the Witwatersrand, Johannesburg, South Africa. ${ }^{3}$ Epidemiology and Public Health Sciences, Department of Public Health and Clinical Medicine, Umeå University, Umeå, Sweden. ${ }^{4}$ World Health Organization, Geneva, Switzerland. ${ }^{5}$ International Network for the Demographic Evaluation of People and their Health (INDEPTH) Network, Accra, Ghana. ${ }^{6}$ KEMRI/Wellcome Trust Research Programme, Centre for Geographic Medicine Research - Coast, Kilifi, Kenya. ${ }^{7}$ Neurosciences Unit, UCL Institute of Child Health, London, United Kingdom. ${ }^{8} \mathrm{Clinical}$ Research Unit, London School of Hygiene and Tropical Medicine, London, United Kingdom. ${ }^{9}$ Department of Psychiatry, University of Oxford, Oxford, United Kingdom. ${ }^{10}$ Priority Cost-effective Lessons for Systems Strengthening (PRICELESS), Johannesburg, South Africa.
Received: 24 March 2015 Accepted: 13 June 2016

Published online: 28 June 2016

\section{References}

1. Ngugi AK, Bottomley C, Kleinschmidt I, Sander JW, Newton CR. Estimation of the burden of active and life-time epilepsy: A meta-analytic approach. Epilepsia. 2010;51:883-90.

2. World Health Organization. Epilepsy in the WHO African Region: Bridging the Gap. Belhocine M, de Boer H, and Mandlhate C. Geneva: World Health Organization; 2004.

3. Ngugi AK, Kariuki SM, Bottomley C, Kleinschmidt I, Sander JW, Newton CR Incidence of epilepsy: a systematic review and meta-analysis. Neurology. 2011;77:1005-12.

4. Carpio A, Bharucha N, Jallon P, Beghi E, Campostrini R, Zorzetto S, Mounkoro P. Mortality of epilepsy in developing countries. Epilepsia. 2005;46:28-32.

5. de Boer HM, Mula M, Sander JW. The global burden and stigma of epilepsy. Epilepsy Behav. 2008;12:540-6.

6. Begley CE, Annegers JF, Lairson DR, Reynolds TF. Estimating the cost of epilepsy. Epilepsia. 1999;40 Suppl 8:8-13.

7. Strzelczyk A, Reese J, Dodel R, Hamer H. Cost of Epilepsy. Pharmacoeconomics. 2008:26:463-76

8. Nsengiyumva G, Druet-Cabanac M, Nzisabira L, Preux PM, Vergnenègre $A$. Economic Evaluation of Epilepsy in Kiremba (Burundi): A Case-Control Study. Epilepsia. 2004;45:673-7.

9. Lagunju IA, Imam ZO, Adedokun BO. Cost of epilepsy in children attending a tertiary centre in Nigeria. Int Health. 2011;3:213-8.

10. Begley $C E$, Beghi E. The economic cost of epilepsy: a review of the literature. Epilepsia. 2002;43 Suppl 4:3-9.

11. Andersen RM. Revisiting the behavioral model and access to medical care: does it matter? J Health Soc Behav. 1995;36:1-10.

12. Donker GA, Foets M, Spreeuwenberg P. Epilepsy patients: health status and medical consumption. J Neurol. 1997;244:365-70.

13. Wiebe S, Bellhouse DR, Fallahay C, Eliasziw M. Burden of epilepsy: the Ontario Health Survey. Can J Neurol Sci. 1999:26:263-70.

14. Meyer A-C, Dua T, Ma J, Saxena S, Birbeck G. Global disparities in the epilepsy treatment gap: a systematic review. Bull World Health Organ. 2010;88:260-6.

15. Mbuba CK, Ngugi AK, Newton CR, Carter JA. The epilepsy treatment gap in developing countries: a systematic review of the magnitude, causes, and intervention strategies. Epilepsia. 2008;49:1491-503.

16. Kahn K, Collinson M, Gomez-Olive FX, Mokoena O, Twine R, Mee P, Afolbai SA, Clark BD, Kabudula CW, Khosa A, Khoza S, Shabangu MG, Silaule B, Tibane JB, Wagner RG, Gareen ML, Clark SJ, Tollman SM. Profile: Agincourt Health and Socio-demographic Surveillance System. Int J Epidemiol. 2012;41:988-1001.

17. Collinson MA, Tollman SM, Kahn K. Migration, settlement change and health in post-apartheid South Africa: triangulating health and demographic surveillance with national census data. Scand J Public Health Suppl. 2007;69:77-84.

18. Cullinan K. Health Services in South Africa: A Basic Introduction. Health-e News Services, January 2006. http://www.health-e.org.za/uploaded/ cb1f388f3b351708d915c12cfb4fc3cf.pdf.

19. Standard Treatment Guidelines and Essential Medicine List for South Africa Primary Health Care. 5th ed. Pretoria South Africa: The National Department of Health; 2014.

20. Wagner RG, Ngugi AK, Twine R, Bottomley C, Kamuyu G, Gómez-Olivé FX, Connor MD, Collinson M a, Kahn K, Tollman S, Newton CR. Prevalence and Risk Factors for Active Convulsive Epilepsy in rural northeast South Africa. Epilepsy Res. 2014:108:782-91.

21. Ameh S, Gómez-Olivé FX, Kahn K, Tollman SM, Klipstein-Grobusch K. Predictors of health care use by adults 50 years and over in a rural South African setting. Glob Health Action. 2014;7:24771.

22. Reid AY, Metcalfe A, Patten SB, Wiebe S, Macrodimitris S, Jetté N. Epilepsy is associated with unmet health care needs compared to the general population despite higher health resource utilization-a Canadian population-based study. Epilepsia. 2012;53:291-300.

23. Gomez-Olive F, Thorogood M, Clark B, Kahn K, Tollman S. Self-reported health and health care use in an ageing population in the Agincourt sub-district of rural South Africa. Glob Health Action. 2013;6:181-92.

24. Bassili A, Omar T, Zaki A. Pattern of diagnostic and therapeutic care of childhood epilepsy in Alexandria, Egypt. Int I Qual Heal Care. 2002;14:277-84.

25. Debrock C, Preux PM, Houinato D, Druet-Cabanac M, Kassa F, Adjien C, Avode G, Denis F, Boutros-Toni F, Dumas M. Estimation of the prevalence of epilepsy in the Benin region of Zinvié using the capture-recapture method. Int J Epidemiol. 2000;29:330. 
26. El SG, Newton C, Hartley S. Attitudes and practices of families and health care personnel toward children with epilepsy in Kilifi Kenya. Epilepsy Behav. 2006;8:201-12.

27. Nxumalo N, Alaba O, Harris B, Chersich M, Goudge J. Utilization of traditional healers in South Africa and costs to patients: findings from a national household survey. J Public Health Policy. 2011;32 Suppl 1:S124-36.

28. Goudge J, Gilson L, Russell S, Gumede T, Mills A. The household costs of health care in rural South Africa with free public primary care and hospital exemptions for the poor. Trop Med Int Heal. 2009;14:458-67.

29. Kendall-Taylor N, Kathomi C, Rimba K, Newton CR. Traditional healers and epilepsy treatment on the Kenyan coast. Epilepsia. 2008;49:1638-9.

30. Mbuba C, Ngugi AK, Fegan G, Ibinda F, Muchohi SN, Nyundo C, Odhiambo R, Edwards T, Odermatt P, Carter JA, Newton CR. Risk factors associated with the epilepsy treatment gap in Kilifi, Kenya: a cross-sectional study. Lancet Neurol. 2012:11:688-96.

31. Cameron A, Bansal A, Dua T, Hill SR, Moshe SL, Mantel-Teeuwisse AK, Saxena S. Mapping the availability, price, and affordability of antiepileptic drugs in 46 countries. Epilepsia. 2012;53:962-9.

32. Lhatoo SD, Sander JW a S. Cause-specific mortality in epilepsy. Epilepsia. 2005;46 Suppl 1:36-9.

33. Beghi E, Garattini L, Ricci E, Cornago D, Parazzini F. Direct cost of medical management of epilepsy among adults in Italy: a prospective cost-of-illness study (EPICOS). Epilepsia. 2004;45:171-8.

34. Tetto A, Manzoni P, Millul A, Beghi E. The costs of epilepsy in Italy: a prospective cost-of-illness study in referral patients with disease of different severity. Epilepsy Res. 2002:48:207-16.

35. Begley C, Annegers J, Lairson D. Methodological issues in estimating the cost of epilepsy. Epilepsy Res. 1999;33:39-55.

36. Liu J, Liu Z, Meng F. The economic burden of epilepsy in a sample of people with epilepsy in China. Epilepsy Res. 2013;103:288-93.

\section{Submit your next manuscript to BioMed Central and we will help you at every step:}

- We accept pre-submission inquiries

- Our selector tool helps you to find the most relevant journal

- We provide round the clock customer support

- Convenient online submission

- Thorough peer review

- Inclusion in PubMed and all major indexing services

- Maximum visibility for your research

Submit your manuscript at www.biomedcentral.com/submit

) Biomed Central 